\title{
On the feasibility of the use of wind SAR to downscale waves on shallow water
}

\author{
O. Q. Gutiérrez ${ }^{1}$, F. Filipponi ${ }^{2}$, A. Taramelli ${ }^{2}$, E. Valentini ${ }^{2}$, P. Camus ${ }^{1}$, and F. J. Méndez ${ }^{1}$ \\ ${ }^{1}$ Environment Hydraulics Institute IH Cantabria, Universidad de Cantabria, Santander, Spain \\ ${ }^{2}$ Department of Prevention and Mitigation of Impacts, ISPRA Institute for Environmental Protection and Research, Rome, \\ Italy
}

Correspondence to: F. Filipponi (federico.filipponi@gmail.com)

Received: 14 May 2015 - Published in Ocean Sci. Discuss.: 23 July 2015

Revised: 16 November 2015 - Accepted: 4 December 2015 - Published: 15 January 2016

\begin{abstract}
In recent years, wave reanalyses have become popular as a powerful source of information for wave climate research and engineering applications. These wave reanalyses provide continuous time series of offshore wave parameters; nevertheless, in coastal areas or shallow water, waves are poorly described because spatial resolution is not detailed. By means of wave downscaling, it is possible to increase spatial resolution in high temporal coverage simulations, using forcing from wind and offshore wave databases. Meanwhile, the reanalysis wave databases are enough to describe the wave climate at the limit of simulations; wind reanalyses at an adequate spatial resolution to describe the wind structure near the coast are not frequently available. Remote sensing synthetic aperture radar (SAR) has the ability to detect sea surface signatures and estimate wind fields at high resolution (up to $300 \mathrm{~m}$ ) and high frequency.

In this work a wave downscaling is done on the northern Adriatic Sea, using a hybrid methodology and global wave and wind reanalysis as forcing. The wave fields produced were compared to wave fields produced with SAR winds that represent the two dominant wind regimes in the area: the bora (ENE direction) and sirocco (SE direction). Results show a good correlation between the waves forced with reanalysis wind and SAR wind. In addition, a validation of reanalysis is shown. This research demonstrates how Earth observation products, such as SAR wind fields, can be successfully uptaken into oceanographic modeling, producing similar downscaled wave fields when compared to waves forced with reanalysis wind.
\end{abstract}

\section{Introduction}

The synergic use of Earth observation (EO) products, wave reanalysis and in situ measurement can be adopted to provide scientific justifications for the appropriate selection of offshore wind farm location. The level-2 SAR (synthetic aperture radar) products can help to better understand the wind fields in open-sea areas (Pieralice et al., 2014), while wave reanalysis and in situ monitoring could be integrated and calibrated using the satellite information. The ability to retrieve wind fields from SAR images, taking advantage of the high resolution (sub-kilometer) and wide coverage $(500 \mathrm{~km})$ offered by wide swath images, represents an important improvement for wave reanalysis applications where knowledge of the wind field is crucial. In recent years, in fact, wave reanalyses have become popular as a powerful source of information for wave climate research and engineering applications. These wave reanalyses provide continuous time series of offshore wave parameters; nevertheless, in coastal areas or shallow water, waves are poorly described because spatial resolution is not detailed (Camus et al., 2013).

\section{Study area}

The Adriatic Sea is a shallow semi-enclosed shelf sea located between western and eastern parts of the Mediterranean Sea; it is about $800 \mathrm{~km}$ long and $150 \mathrm{~km}$ wide. The northern Adriatic Sea is a shallower area (depth $<50 \mathrm{~m}$ ) and has a gentle slope (about $0.02^{\circ}$ ). Figure 1 shows the study area and the wind wake patterns from $\sigma_{0}$ SAR intensity of the ENVISAT ASAR WS image acquired on 2 February 2012, 
20:59:29 UTC; the rectangle indicates the downscaling area and the location of a wave buoy with available data for validation.

The general cyclonic water circulation system of the northern Adriatic Sea is highly variable with seasons (Artegiani et al., 1997; Zavatarelli and Pinardi, 2003; Pullen et al., 2003). One of the major features is a coastal current along the western side of the basin, the Western Adriatic Coastal Current (WACC), driven by wind and thermohaline forcing (Poulain, 2001). In the northern Adriatic Sea, the main forcings of waves are the local winds. Two distinct wind regimes, bora and sirocco, dominate conditions in the area and influence basin-wide circulation (Orlić et al., 1994). Bora is a downwelling favorable wind that blows from ENE with a mean speed of $15 \mathrm{~m} \mathrm{~s}^{-1}$; it shows an evident interannual variability (Bignami et al., 2007) and can generate large waves with significant wave heights up to $1 \mathrm{~m}$ and periods up to $5 \mathrm{~s}$ (Cavaleri et al., 1997). In contrast, sirocco is an upwelling favorable wind that blows from SE with a typical speed of $10 \mathrm{~m} \mathrm{~s}^{-1}$. Sirocco wind brings warm Mediterranean air (Orlić et al., 1994) and generates lower wave height than bora but a longer wave period on the order of $10 \mathrm{~s}$ in the northern Adriatic Sea region (Wang et al., 2007). It has an available fetch of several hundreds of kilometers and is thus particularly efficient in modulating the wave field, more so than bora, whose fetch is restricted to the narrow width of the Adriatic Sea (Cavaleri et al., 1997; Signell et al., 2005).

Bignami et al. (2007) pointed out that the inhomogeneity in bora wind speed distribution is not equally represented by the wind products at different spatial resolutions. Atmospherical models do not represent the detailed range of bora wind spatial variability, like the dual-jet nature of the Trieste jet or the several-kilometer-wavelength structures in the Bakar and Senj jet regions. Estimated wind fields at fine scale from SAR satellite allow the observation of morphology, wake patterns, the formation of the barrier jet on the western Adriatic coast and, where present, dual-jet structure of the bora wind (Signell et al., 2010; Adamo et al., 2013).

\section{Materials}

\subsection{Wind}

\subsubsection{Wind reanalysis}

SEAWIND I reanalysis is a regional dynamical atmospheric downscaling that covers the North Atlantic and Mediterranean regions. Simulations were done using the Weather Research and Forecasting (WRF) model (version 3.1.1) with the Advanced Research dynamical solver (WRF-ARW) (Skamarock et al., 2008). The resolution of modeled wind fields in the reanalysis is defined with 40 vertical hybrid levels (first 7 levels below the first $1000 \mathrm{~m}$ ) and $30 \mathrm{~km}$ horizontal resolution. The database spans from January 1948 to March 2013.
This reanalysis has been validated for sea winds comparing the database with in situ buoys and satellite data. The in situ measurements from buoys used in this process come from the REDEXT and REMPOR network of buoys and meteorological stations from Puertos del Estado (Spanish National Ports and Harbour Authority). Also, satellite data from ERS2 (1995-2003), Envisat (2002), GFO (2000-2008), Jason1 (2002), Jason-2 (2008) and $T \cdot P^{-1}(1992-2005)$ were used for validation.

\subsubsection{Wind SAR fields}

Wind field products have been collected from the SOPRANO service, developed by CLS (Collecte Localization Satellites). Envisat ASAR wide-swath mode data VV polarized have been processed using SAR2WNF software v.3.0.0. The scattering model used to estimate wind field from normalized radar cross section (NRCS) is CMOD-IFR2 (Quilfen et al., 1998). The model, developed for VV-polarized C-band scatterometry, makes use of NRCS together with a priori wind direction from the ECMWF $33 \mathrm{~h}$ wind forecast at $0.25^{\circ}$ resolution.

For the retrieval of the SAR data archive, in order to investigate the ability of the SAR for the wind and wave productions, the following criteria were used for data collection:

1. collection of all SAR data involving critical events in the northern Adriatic basin;

2. selection of SAR data in relation to the existence of ground truth data or obtained from other EO sources (VHR (very high resolution) optical satellite data); and

3. selection of SAR data based on information provided by weather and sea reanalysis.

A total of 15 high-resolution wind fields at $0.01^{\circ}$ spatial resolution, estimated from satellite SAR acquired between December 2011 and April 2012, have been used as forcing in wind wave modeling. Figure 2 shows the available wind SAR fields for forcing the model. The transport of Stokes, as well as the wind, especially at the end of January 2012, retained the same direction for many days, increasing in intensity thanks to a bora that was blowing in those days.

\subsection{Waves}

The Global Ocean Waves (GOW) reanalysis is a historical reconstruction of ocean waves. GOW has been generated from the WaveWatch III spectral model (Tolman, 1989, and Tolman, 1997). Spectral wave models have a level of accuracy that enables reproduction of significant wave height and peak period with errors below $15 \%$. WaveWatch III is a thirdgeneration wave model developed at NOAA-NCEP (Tolman, 2009a, b). It solves the spectral action density balance equation for wave-number direction spectra. The model can generally be applied to large spatial scales and outside the surf 


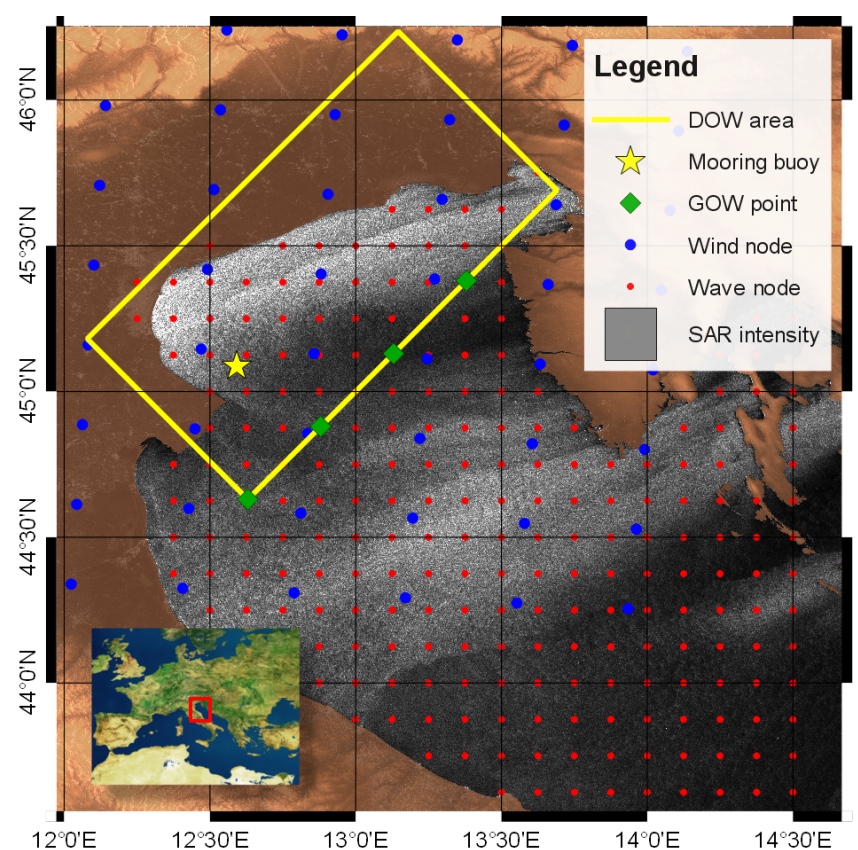

Figure 1. Modeled domain in the northern Adriatic Sea basin. Background shows $\sigma_{0}$ of the ENVISAT ASAR WS image acquired on 2 February 2012, 20:59:29 UTC.

zone. Parameterizations of physical processes include wave growth and decay due to the actions of wind, nonlinear resonant interactions, dissipation (whitecapping) and bottom friction. Bathymetry, ice cover and wind forcing databases are crucial for a good historical hindcast of ocean waves.

GOW encompasses several hourly reanalysis projects at different spatial resolutions: a global wave reanalysis as well as several regional wave reanalyses in Europe (Fig. 3) and Latin America. An adequate configured model and input forcing have been used for each project. Detailed information about particular GOW projects can be found in Reguero et al. (2012). In particular, the GOW used in this work (whose domain is identified with the dashed line in Fig. 3) was forced with the CFSR reanalysis and spans from 1979 to the present. The grid resolution in the Mediterranean Sea is $0.18^{\circ}$ $(20 \mathrm{~km})$. This database was validated using satellite and buoy data, finding correlations larger than 0.95 and a scatter index lower than 0.15 along the Atlantic coast.

\subsection{In situ data set}

In situ data used for validation of downscaled waves were collected from a mooring buoy located at the GNL terminal (yellow mark in Fig. 1), acquiring hourly the following parameters: wave height, wave direction, and wave period.

\section{Methods}

The methodology used in this work is divided into two main parts: in the first part wave downscaling is done, and in the second part, the SAR wind fields are used to force the numerical model. The wave downscaling was done following the hybrid methodology described in Camus et al. (2011a) in which a small number of waves and wind conditions were selected by means of the maximum dissimilitude method. Wave propagation was done using the SWAN model (Booij et al., 1999); then, wave time series were reconstructed using radial basis function interpolation.

Finally, 15 high-resolution wind fields, estimated from satellite SAR acquired between December 2011 and April 2012 corresponding to transient occurrences of the main wind regimes with a typical duration of several days, were used for wave downscaling. As results, the wave fields forced with modeled wind fields and with wind SAR fields were compared. The development of the Downscaled Ocean Waves (DOW) database implies several steps, which are summarized in Fig. 4. The steps of the proposed global framework are (a) analysis of the reanalysis databases available in the study area, (b) calibration of the reanalysis databases in deep water with instrumental data, (c) selection of a limited number of cases that are the most representative of wave and wind hourly conditions in deep water, (d) propagation of the selected cases using a wave propagation model, (e) reconstruction of the time series of sea state parameters in shallow water, (f) validation of the coastal wave data with instrumental data, and $(\mathrm{g})$ characterization of wave climate by means of a statistical technique. This methodology was developed at the IH Cantabria (Camus et al., 2011a) and has been applied to downscale waves in Spain, Brazil, and Oman.

The second part of the work consists of the wave simulation of bora and sirocco events observed in the SAR wind fields. This was done using the same domain as in the downscaling and the wave climate on the open boundary. As there are only 15 SAR wind fields, every wind field is treated as a single simulation and the instantaneous wind field as the mean wind field during a $1 \mathrm{~h}$ sea state.

\subsection{Wave downscaling}

\subsubsection{Setting}

The methodology described in Fig. 4 was applied to the northern Adriatic Sea. As inputs, the GOW Mediterranean (Reguero et al., 2012) grid (Fig. 3) with a spatial resolution of $0.18^{\circ}(20 \mathrm{~km})$ and the Seawind I database (Menéndez et al., 2013) with a spatial resolution of $30 \times 30 \mathrm{~km}$ (Fig. 1) were used.

The domain is small enough so that wave propagation across the area occurs at a faster rate than the change in offshore forcing at the domain boundary; therefore, stationary conditions for wave simulations can be assumed. The dimen- 

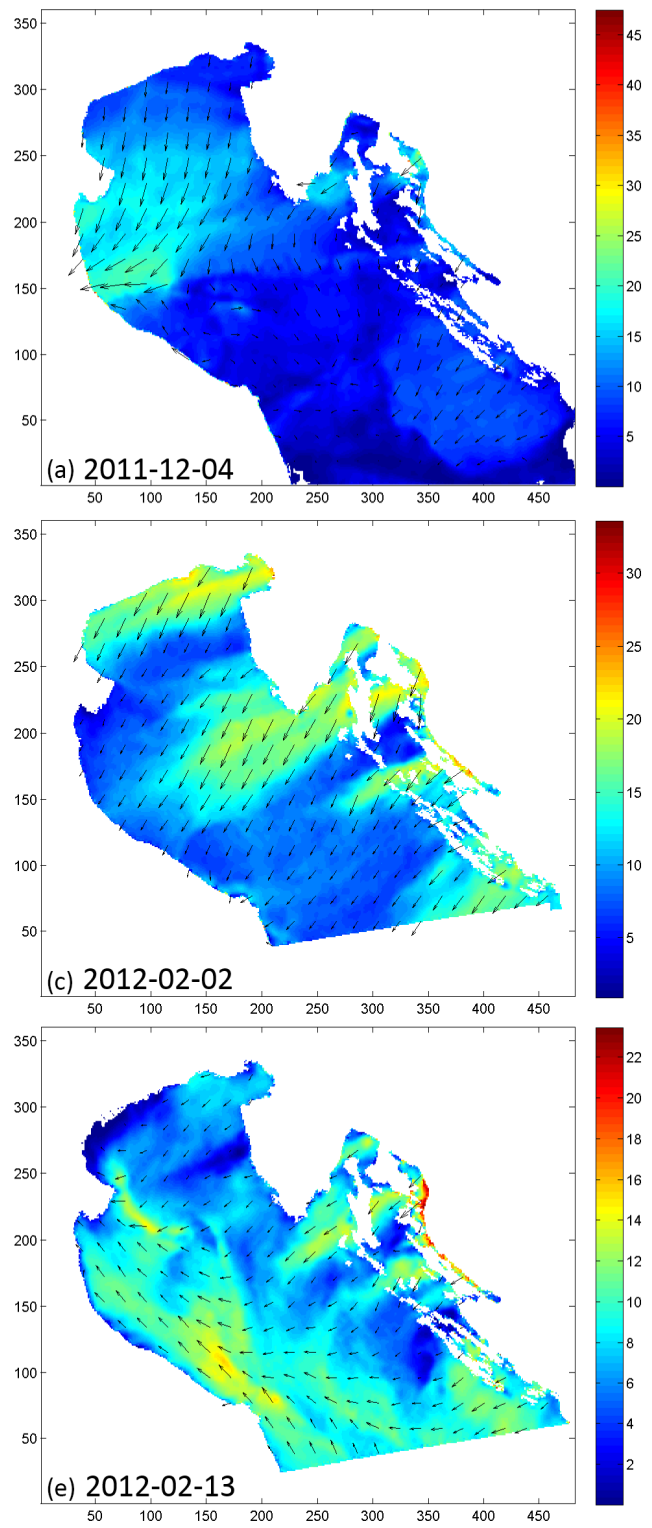
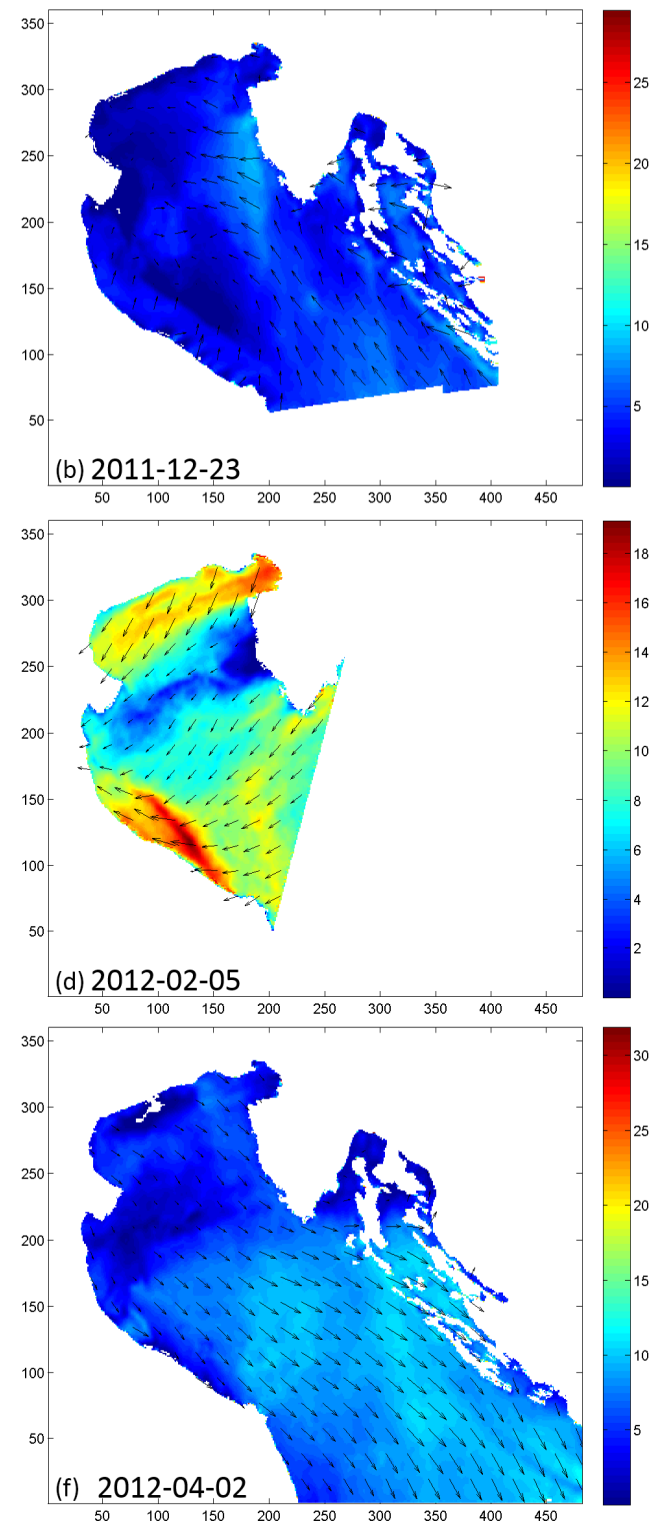

Figure 2. Some of the $15 \mathrm{SAR}$ wind fields available for wave simulation.

sions of the downscaling grid (Fig. 1) are $166 \times 110$ points with a resolution of $1 \mathrm{~km}$. The bathymetry of the dynamical downscaling grids is defined by means of the global General Bathymetric Chart of the Oceans (GEBCO) bathymetry, with a spatial resolution of $1^{\prime}$ from a combination of sounding waves and satellite data, available at the British Data Centre (BDOC).

Wave climate definition for the open boundary of downscaling was obtained from the GOW database. The output parameters of GOW are the significant wave height $\left(H_{\mathrm{S}}\right)$, the peak period $\left(T_{\mathrm{p}}\right)$, mean wave direction $\left(\theta_{\mathrm{m}}\right)$ and the directional energy spectra in the boundaries of the DOW grid. Figure 1 shows the location where the input boundary conditions were obtained.

\subsubsection{Calibration}

Due to insufficient resolution of forcing wind fields and spatial and temporal model resolutions, a parametric calibration was done following Mínguez et al. (2011). This method corrects significant wave heights with instrumental data from satellites according to the mean wave direction. The model is shown in Eq. (1).

$H_{\mathrm{s}}^{C}=a^{R}(\theta)\left[H_{\mathrm{s}}^{R}\right]^{b^{R}(\theta)}$,

where $H_{\mathrm{s}}^{R}$ is the reanalysis significant wave height, $H_{\mathrm{S}}^{C}$ is the calibrated significant wave height and $a^{R}(\theta)$ and $b^{R}(\theta)$ are the parameters that depend on the mean wave direction $\theta$ 


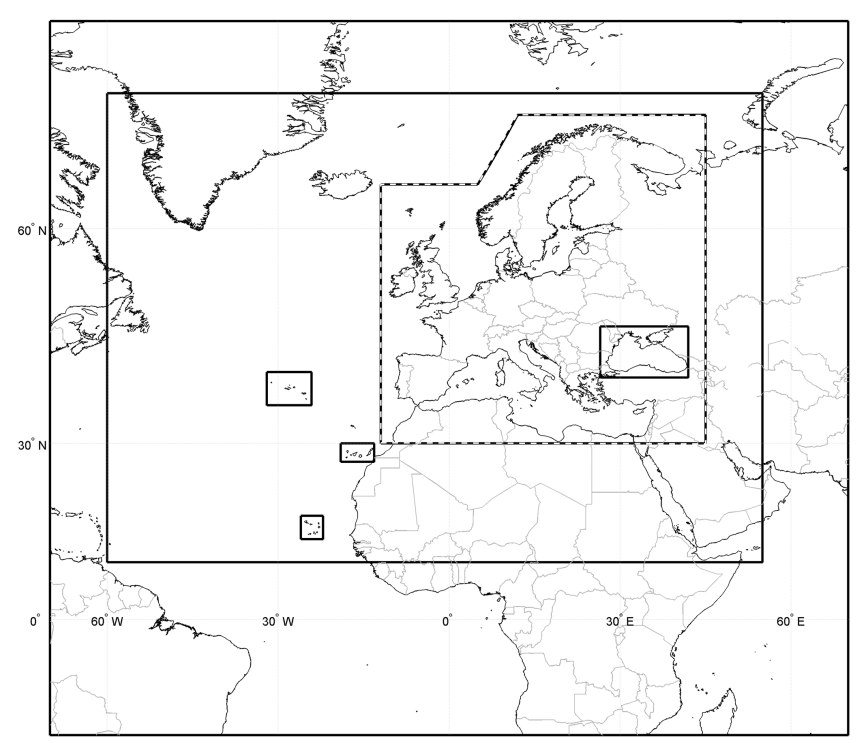

Figure 3. Wave reanalysis domains in Europe.

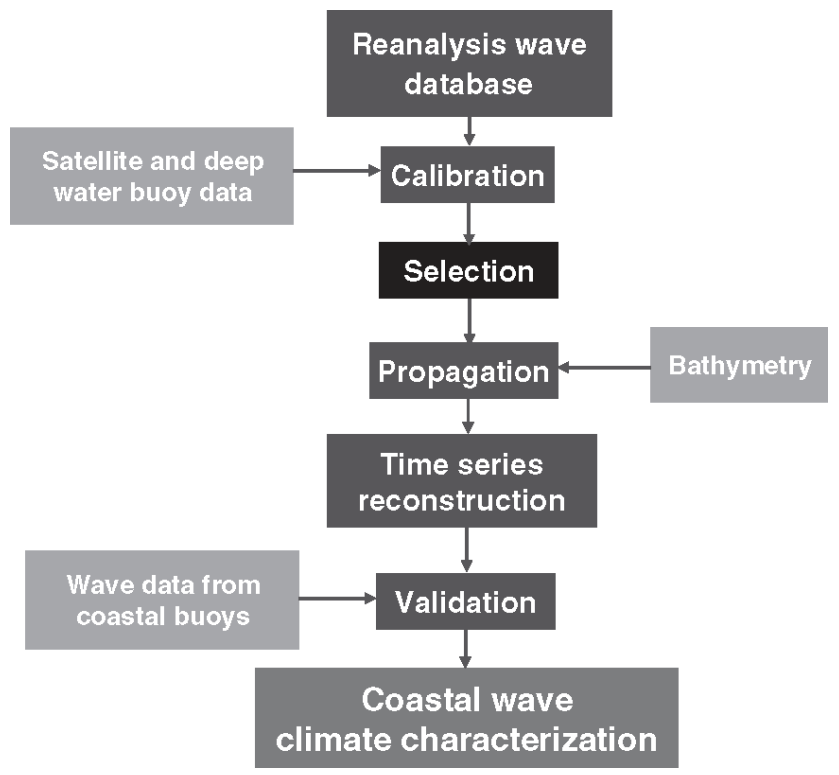

Figure 4. Methodology to downscale wave climate to coastal areas.

from reanalysis. A complete explanation of this methodology can be found in Mínguez et al. (2011).

This correction is applied to each boundary node on the downscaling grid. The pairs of parameters for the calibration were obtained by choosing all the satellite data in a radius of $1.5^{\circ}$.

\subsubsection{Selection}

The selection is made to obtain a set of representative scenarios of ocean conditions of the total database. Selection is made by applying a maximum-dissimilarity algorithm
(MDA). The MDA has been proven to identify the most dissimilarity wave conditions in a reanalysis database including the extreme events. The algorithm and details of selection are described in Camus et al. (2011b).

This part of the methodology has three steps: (i) set wind grid points and wave grid points where forcing is defined for the numerical propagations. Standardize the calibrated data after the wave and wind directions have been transformed into the $x$ and $y$ components. (ii) Apply the principal component analysis to the standardized forcing. Select the number of principal components, i.e., the variables in the new reduced space, which produces an acceptable rootmean-square error reconstruction. (iii) Select a representative number of offshore conditions using the MDA in the reduced space and identify these selected cases in the original space.

The forcing conditions are defined by the wave reanalysis nodes along the domain boundary and the simultaneous wind fields. In this way the wave spatial variability and the local wind wave generation are taken into account. The Mediterranean GOW with a spatial resolution of $0.18^{\circ}$ is used to define the boundaries of the DOW grid; meanwhile, the SeaWind I database is used to define the wind fields. Figure 1 shows the dynamical downscaling grid, the GOW and Seawind nodes. The parameters used in the selection process and in time series reconstruction are the hourly series of wave height $\left(H_{\mathrm{s}}\right)$, the mean wave period $\left(T_{\mathrm{m}}\right)$ and the mean wave direction $\left(\theta_{\mathrm{m}}\right)$ of every node at the computation boundaries, and the hourly series of wind directional components of the nodes at the upper boundary of the wind grid.

To avoid highly correlated situations among grid points of a given variable and among different variables, a principal component analysis (PCA) is done. The PCA reduces the dimension of the data, preserving the maximum variance of the sample data. The selection of the most appropriate number of PCAs is based on the reconstruction root-mean-square error (RMSE) of the offshore wave and wind conditions. In this case, the first 15 principal components explained $99.0 \%$ of the variance of the original database; therefore, the dimensions of the hourly series were reduced from 35 to 15 , with no significant information loss.

The next step consists of selecting a representative subset using MDA. The first element of the selection coincides with the largest significant wave height, identified in the original space. Figure 5 shows the subset of size $M=100$ elements selected in the EOF space. The selected cases are fairly distributed in the data space. This subset, selected by MDA, is not projected back to the original space. The selected elements are identified in the original series of the wave conditions.

\subsubsection{Deep to shallow water transformation}

The representative cases, selected by MDA, of wave climate are propagated to coastal areas using the SWAN numerical model (Booij et al., 1999). For each case, on every DOW 


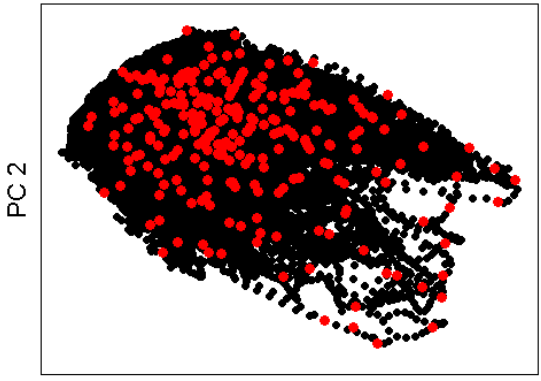

PC 1

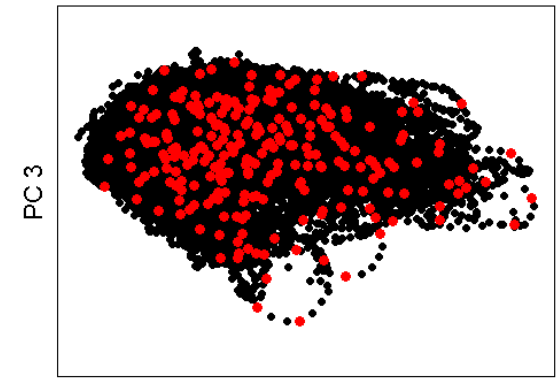

PC 1

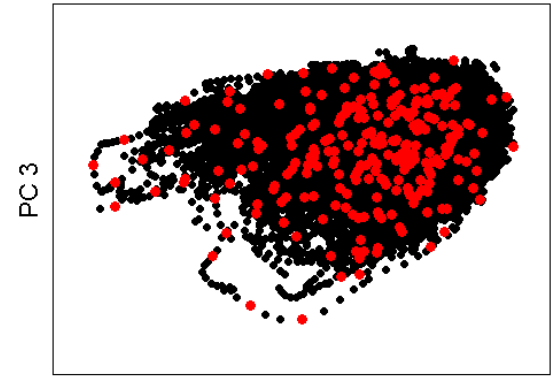

PC 2

Figure 5. Subset of selected cases.

grid node, the propagated significant wave height $\left(H_{\mathrm{sp}, j}\right)$, the peak period $\left(T_{\mathrm{pp}, j}\right)$ and the mean direction $\left(\theta_{\mathrm{mp}, j}\right)$ are stored. Therefore the $M$ propagations in the DOW domain define a catalog of cases formed by the $M=100$ hourly sea state parameters corresponding to a certain sea state condition in deep water.

\subsubsection{Time series reconstruction}

Finally the reconstruction of the time series of wave parameters on the DOW grid is done by means of a radial basis function (RBF) interpolation. A detailed description can be found in Camus et al. (2011a).

\subsection{Wind satellite simulations}

The analysis of SAR wind fields is 2-fold. First, the SAR wind fields were compared to the modeled wind fields in order to highlight the differences between both wind sources. Second, the SAR wind fields were used to force the numerical model and produce wave fields. These simulations were also forced with the corresponding wave climate through the open boundary.

\subsubsection{Wind field comparisons}

The comparison between the SAR wind fields and modeled wind fields cannot be made directly due to the different natures of the measurements. The hourly reanalysis wind fields represent the mean conditions of wind (both in magnitude and in direction) during an hour on a coarse grid. On the other hand, the SAR wind database represents the instantaneous wind fields, namely, the wind field at the exact moment when the satellite overpasses the area, estimated at high spatial resolution. Therefore, to have an adequate comparison between both wind sources, the SAR wind fields were interpolated to the coarse-resolution grid of wind reanalysis, and only qualitative comparisons were made.

\subsubsection{Wave simulations with SAR wind fields}

Simulations were done using the SWAN model, using the same domain as in the previous section and forcing the SAR wind fields and the corresponding wave boundary conditions. These simulations were compared with simulations forced with the SeaWind I reanalysis wind fields. Figure 6 shows some examples of the comparisons between the wave fields forced with SAR winds and reanalysis winds.

\section{Results and discussion}

The principle of wind and wave reconstruction is based on the estimation of suitable parameters that characterize the signal and, in the case of the SAR, radar and other EO systems. More specifically, the ratio signal/clutter is a set of interference signals that can not be traced back to the target and that generally worsen the contrast between target and background of the target and that highlight the SAR wind data. A high similarity was found between the SAR wind field and the reanalysis wind field; this suggests that there is a high persistence of wind direction during a time step of $1 \mathrm{~h}$ (Fig. 7). Although there are cases where wind sources show opposite directions, due to low resolution of the modeled winds, a good correlation was found on the downscaled waves.

Thus the estimation of wind fields obtained by means of a Bayesian approach (Adamo et al., 2014) exploits both the radar cross section of the normalized SAR and external information, such as the fields of wind meteorological models (Numerical Weather Product). Results show that although SAR wind fields were able to solve fine-scale spatial patterns and improve wave downscaling in the study area, especially during bora wind events due to complex orography on the Istrian coast, the following weaknesses were found:

- the domain is not always fully covered by satellite acquisitions, even using wide swath acquisition modes;

- the estimated wind fields represent the instantaneous conditions of winds, and not the mean condition during $1 \mathrm{~h}$ (requirement for wave downscaling); and 

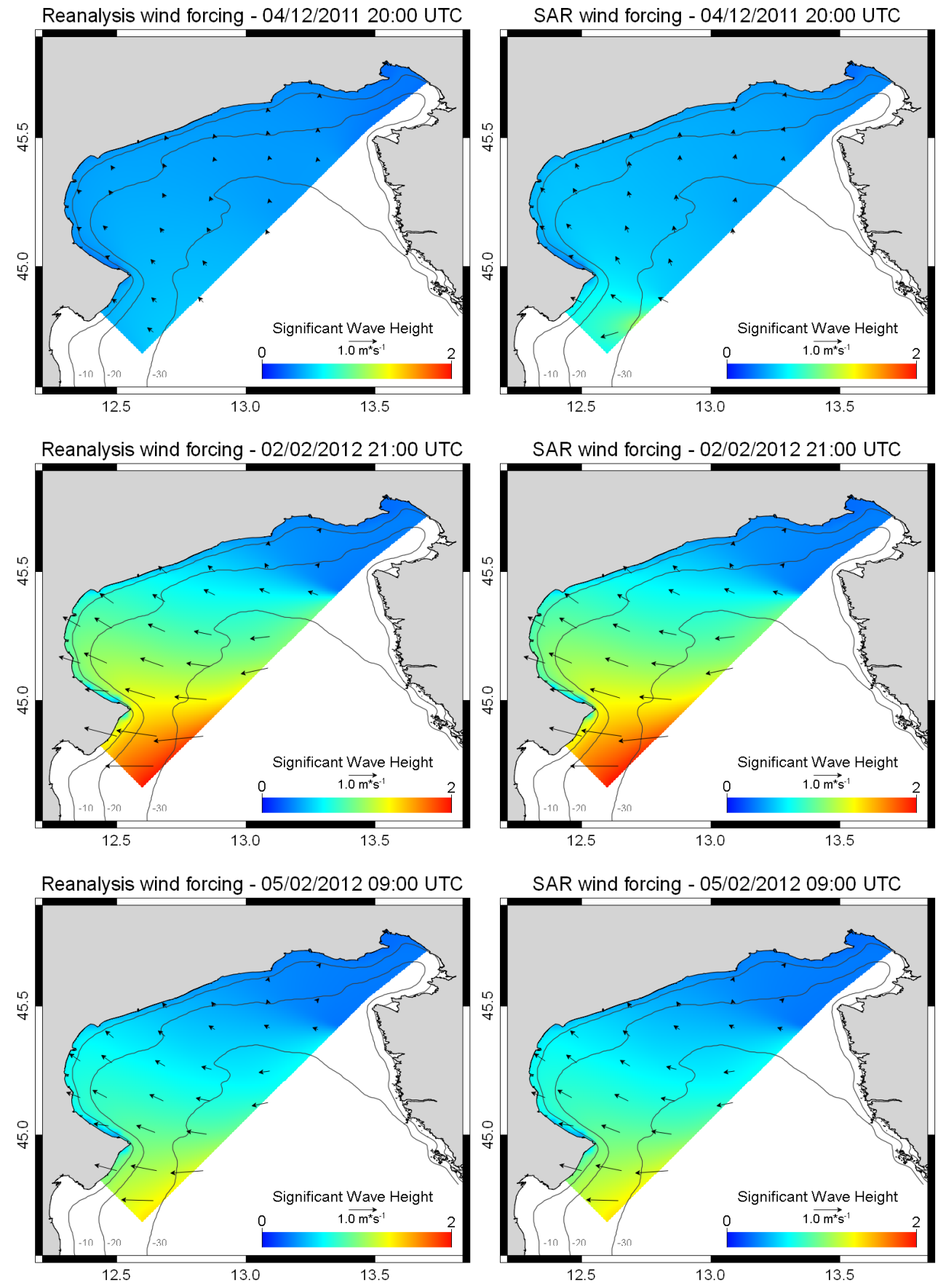

Figure 6. Some cases of wave fields forced with reanalysis winds (left) and SAR winds (right). Solid isolines are the bathymetric contour lines.

- temporal resolution is limited (one observation every 316 days), while typically hourly data are required for wave downscaling.

To solve the temporal resolution issue, the use of a blended wind product from either SAR wind or modeled wind may represent a solution to supply the SWAN model with consis- tent wind forcing, as successfully demonstrated in Benassai et al. (2015).

The algorithm used for wind field estimation from Sentinel-1 data is s-1 owi, which makes use of the CMODIFR2 neural-network-based GMF (geophysical model function). Although CMOD5.N GMF for SAR wind estimation has the smallest bias and root-mean-square error based on the recent literature, all of the GMFs exhibit a negative bias 

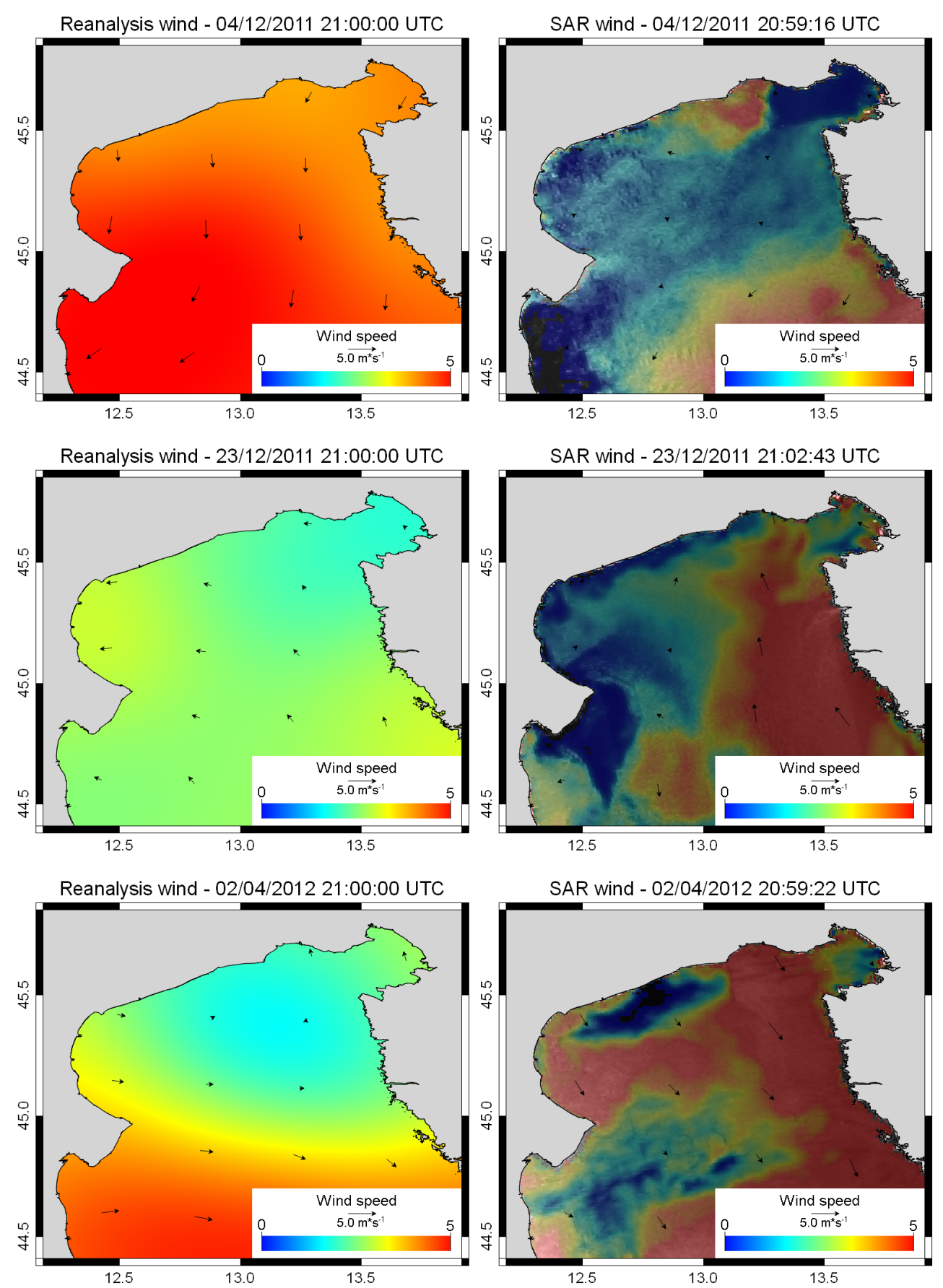

Figure 7. Examples of wind fields with similar patterns between SAR and reanalysis. SAR wind fields (right) are superimposed to the corresponding $\sigma_{0}$ SAR intensity.

in the retrieved wind speed (Takeyama et al., 2013). This research study is in the context of operational oceanography research development for the Copernicus CMEMS service, and therefore made use of a wind forcing data set similar to what oceanographers will operationally use from Sentinel1A SAR-derived products.
As validation of propagated waves, a series of wave heights was reconstructed in the buoy location and compared with in situ measurements. Figure 8 shows a 6-month segment (winter 2011 to spring 2012) of both observed and modeled wave height series. During this period the correlation between reanalysis and data buoy is $87 \%$, the simulation being able to reproduce events of high and low wave height 


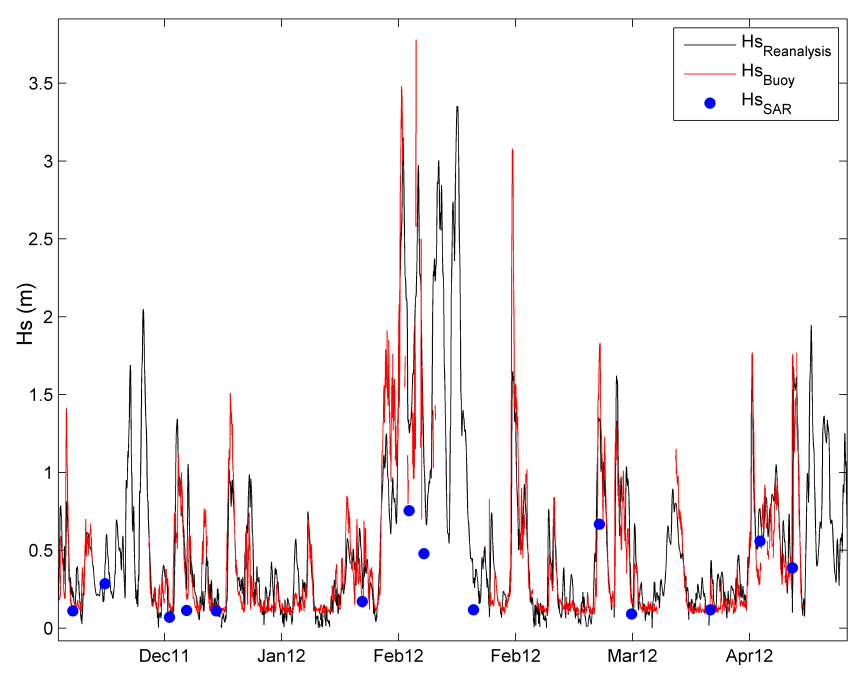

Figure 8. Comparison between the downscaled wave height series and the buoy wave height.

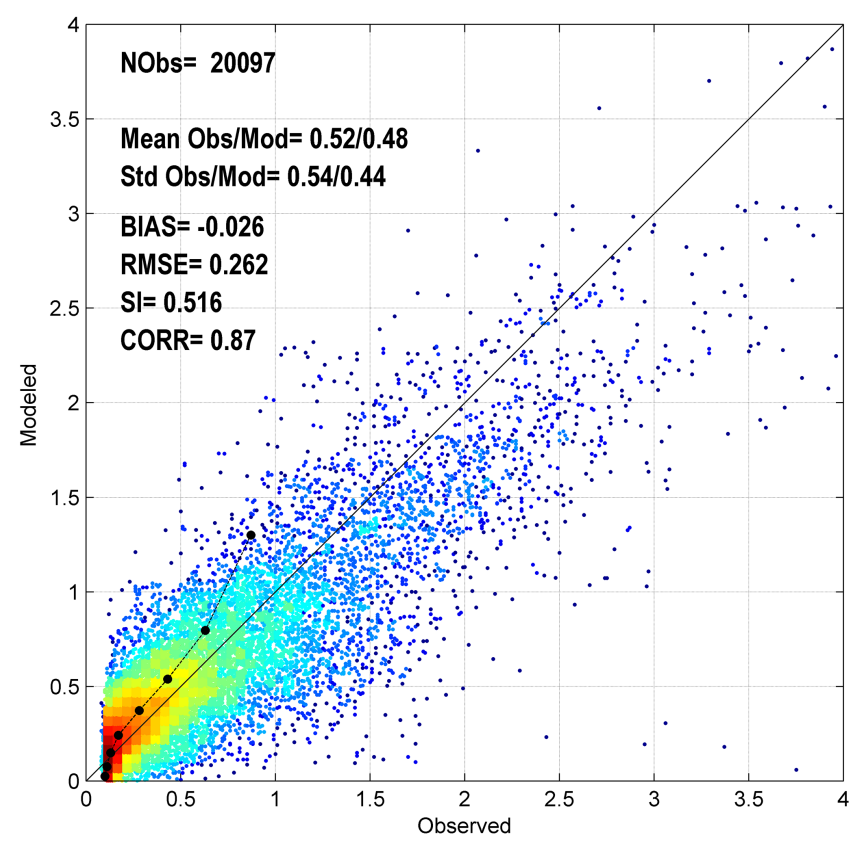

Figure 9. Quantile-quantile plot of observed and downscaled wave height.

events. In the same figure, blue dots indicate the wave height obtained using the SAR wind fields as forcing. It can be observed that SAR wind simulations depict the same behavior of time series, although some of these correspond to periods of small waves or relative calms.

Figure 9 shows scatter and quantile-quantile (20 equally distributed Gumbel quantiles) plots of the measured versus modeled Hs, for the entire data set of buoys indicating the general good quality of the results obtained. Several diagnosis statistics are calculated to compare model performance

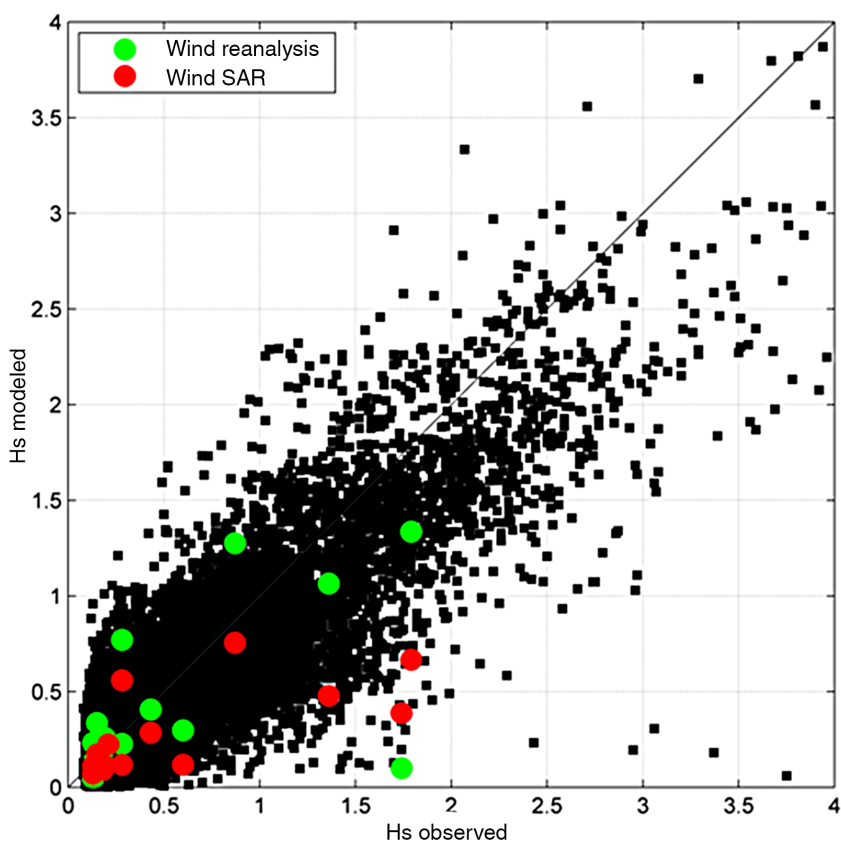

Figure 10. Quantile-quantile plot of observed and downscaled wave height including the SAR wind cases (red marks) compared to their respective modeled wind cases (green marks).

with respect to instrumental data, such as the RMSE, the Pearson correlation coefficient $(\rho)$, the systematic deviation between two random variables (BIAS) and the residual scatter index (SI). Finally, Fig. 10 incorporates into the scatter plot the downscaled wave heights simulated using SAR wind (red points) and the modeled wind (green points). In general, both simulations of the sea states, where SAR winds were available, describe statistically equivalent results for the wave height, although for larger waves, modeled winds produce larger waves than SAR winds. Nevertheless, there are not enough intense wind stress cases to find a statistically robust trend.

In comparison with previous experimental research $(\mathrm{Ca}-$ mus et al., 2011a), results from this work show the ability of SAR satellite data to force time series of wave fields by means of an RBF interpolation. Considering previous attempts to force wave simulations using SAR wind (Benassai et al., 2013, 2015), advancement was reached using an efficient methodology to downscale waves on shallow water in mid-term simulations (days to months).

\section{Conclusions}

A wave climate downscaling of the northern Adriatic Sea was done by applying the methodology described in Camus et al. (2011a). The downscaling was forced with a regional wind reanalysis (SeaWind I) and a global reanalysis of waves (GOW Mediterranean). The downscaling was done using a 
hybrid methodology that consists of the selection of a set of wave climate cases by means of the maximum dissimilitude technique, the propagation of these cases, and finally the reconstruction of time series by means of radial basis functions. Several SAR wind fields were analyzed and used to force the model to propagate the wind waves in the downscaled area.

Comparison with in situ instrumental data indicates the general good quality of the downscaled waves. Although there are differences between SAR and modeled wind fields, a good correlation was found on the downscaled waves forced with different wind fields.

This research demonstrates how EO products, such as SAR wind fields, can be successfully up-taken into oceanographic modeling, as well as reconstruct time series of wave fields using RBF interpolation. Operational Sentinel-1 will produce a consistent long-term data archive (Level-2-Ocean) built for these applications based on long time series, opening the way for new improvements in services for operational oceanography.

Acknowledgements. The support of the European Commission through projects GIO Lot2 User Uptake (DG-ENTERPRISES) and Innovative Multi-purpose offshore platforms: planning, design and operation (MERMAID), contract 288710, FP7-OCEAN.2011-1, www.mermaidproject.eu, is gratefully acknowledged. O. Q. Gutiérrez and F. J. Méndez acknowledge the support of the Spanish Ministerio de Economía y Competitividad under grant BIA201459643-R.

Edited by: V. Brando

\section{References}

Adamo, M., De Carolis, G., Morelli, S., and Rana, F.: Combined observations of a Bora event in the Adriatic Sea by means of ETA model and SAR data, Geophysical Research Abstracts, Vol. 15, EGU2013-5062, 2013 EGU General Assembly, Vienna, Austria, eISSN: 1029-7006, 7-12 April 2013.

Adamo, M., Rana, F. M., De Carolis, G., and Pasquariello, G.: Assessing the Bayesian inversion technique of C-band synthetic aperture radar data for the retrieval of wind fields in marine coastal areas, J. Appl. Remote Sens., 8, 083531-083531, doi:10.1117/1.JRS.8.083531, 2014.

Artegiani, A., Paschini, E., Russo, A., Bregant, D., Raicich, F., and Pinardi, N.: The Adriatic Sea general circulation. Part II: baroclinic circulation structure, J. Phys. Oceanogr., 27, 1515-1532, 1997.

Benassai, G., Montuori, A., Migliaccio, M., and Nunziata, F.: Sea wave modeling with X-band COSMO-SkyMed ${ }^{\circledR}$ SAR-derived wind field forcing and applications in coastal vulnerability assessment, Ocean Sci., 9, 325-341, doi:10.5194/os-9-325-2013, 2013.

Benassai, G., Migliaccio, M., and Nunziata, F.: The use of COSMOSkyMed $^{\circledR}$ SAR data for coastal management, J. Marine Sci. Technol., 20, 542-550, doi:10.1007/s00773-015-0309-2, 2015.
Bignami, F., Sciarra, R., Carniel, S., and Santoleri, R.: Variability of Adriatic Sea coastal turbid waters from SeaWiFS imagery, J. Geophys. Res.-Oceans, 112, C03S10, doi:10.1029/2006JC003518, 2007.

Booij, N., Ris, R. C., and L. H. Holthuijsen, L. H.: A thirdgeneration wave model for coastal regions. Part I: model description and validation, J. Geophys. Res., 104, 7649-7666, 1999.

Camus, P., Méndez, F. J., and Medina, R.: A hybrid efficient method to downscale wave climate to coastal areas, Coast. Eng., 58, 851862, 2011a.

Camus, P., Méndez, F. J., Medina, R., and Cofiño, A. S.: Analysis of clustering and selection algorithms for the study of multivariate wave climate, Coast. Eng., 58, 453-462, 2011 b.

Camus, P., Méndez, F. J., Medina, R., Tomas, A., and Izaguirre, C.: High resolution DOWNSCALED OCEAN WAVES (DOW) reanalysis in coastal areas, Coast. Eng., 72, 56-68, 2013.

Cavaleri, L., Curiotto, S., Mazzoldi, A., and Pavanati, M.: Long term directional wave recording in the Northern Adriatic Sea, Nuovo cimento della Società italiana di fisica, C, 20, 103-110, 1997.

Menéndez, M., García-Díez, M., Fita, L., Fernández, J., Méndez, F. J., and Gutiérrez, J. M.: High-resolution sea wind hindcasts over the Mediterranean area, Clim. Dynam., 42, 1857-1872, doi:10.1007/s00382-013-1912-8, 2013.

Mínguez, R., Espejo, A., Tomás, A., Méndez, F. J., and Losada, I. J.: Directional calibration of wave reanalysis databases using instrumental data, J. Atmos. Ocean. Tech., 28, 1466-1485, doi:10.1175/JTECH-D-11-00008.1, 2011.

Orlić, M., Kuzmić, M., and Pasarić, Z.: Response of the Adriatic Sea to the bora and sirocco forcing, Cont. Shelf Res., 14, 91116, 1994.

Pieralice, F., Proietti, R., Valle, P. L., Giorgi, G., Mazzolena, M., Taramelli, A., and Nicoletti, L.: An innovative methodological approach in the frame of Marine Strategy Framework Directive: a statistical model based on ship detection SAR data for monitoring programmes, Mar. Environ. Res., 102, 18-35, 2014.

Poulain, P. M.: Adriatic Sea surface circulation as derived from drifter data between 1990 and 1999, J. Marine Syst., 29, 3-32, 2001.

Pullen, J., Doyle, J. D., Hodur, R., Ogston, A., Book, J. W., Perkins, H., and Signell, R.: Coupled ocean-atmosphere nested modeling of the Adriatic Sea during winter and spring 2001, J. Geophys. Res.-Oceans, 108, 3320, doi:10.1029/2003JC001780, 2003.

Quilfen, Y., Chapron, B., Elfouhaily, T., Katsaros, K., and Tournadre, J.: Observation of tropical cyclones by high-resolution scatterometry, J. Geophys. Res., 103, 7767-7786, 1998.

Reguero, B. G., Menéndez, M., Méndez, F. J., Mínguez, R., and Losada, I. J.: A global ocean wave (GOW) calibrated reanalysis from 1948 onwards, Coast. Eng., 65, 38-55, 2012.

Signell, R. P., Carniel, S., Cavaleri, L., Chiggiato, J., Doyle, J. D., Pullen, J., and Sclavo, M.: Assessment of wind quality for oceanographic modelling in semi-enclosed basins, J. Marine Syst., 53, 217-233, 2005.

Signell, R. P., Chiggiato, J., Horstmann, J., Doyle, J. D., Pullen, J., and Askari, F.: High-resolution mapping of Bora winds in the northern Adriatic Sea using synthetic aperture radar, J. Geophys. Res.-Oceans, 115, C04020, doi:10.1029/2009JC005524, 2010.

Skamarock, W. C., Klemp, J. B., Dudhia, J., Gill, D. O., Baker, D. M., Duda, M. G., Huang, X.-Y., Wang, W., and Powers, J. G.: 
A description of the advanced research WRF version 3, NCAR Tech. Note NCAR/TN-475+STR, National Center For Atmospheric Research Co Mesoscale and Microscale Meteorology Division, Boulder, Colorado, USA, 125, doi:10.5065/D68S4MVH, 2008.

Takeyama, Y., Ohsawa, T., Kozai, K., Hasager, C. B., and Badger, M.: Comparison of geophysical model functions for SAR wind speed retrieval in Japanese coastal waters, Remote Sensing, 5, 1956-1973, doi:10.3390/rs5041956, 2013.

Tolman, H. L.: The numerical model WAVEWATCH: a third generation model for the hindcasting of wind waves on tides in shelf seas, Communications on Hydraulic and Geotechnical Engineering, Delft Univ. of Techn., Rep. no. 89-2, ISSN 0169-6548, 1989.

Tolman, H. L.: User manual and system documentation of WAVEWATCH-III version 1.15, NOAA/NWS/NCEP/OMB Technical Note Nr. 151, National Oceanic and Atmospheric Administration Co National Centers For Environmental Prediction, Washington, USA, 1997.
Tolman, H. L.: Distributed memory concepts in the wave model WAVEWATCH III, version 3.14, NOAA/NWS/NCEP/MMAB Technical Note, Technical Note Nr. 276, National Oceanic and Atmospheric Administration Co National Centers For Environmental Prediction, Washington, USA, 2009a.

Tolman, H. L.: User manual and system documentation of WAVEWATCH III version 2.22, NOAA/NWS/NCEP Technical Note, 2009b.

Wang, X. H., Pinardi, N., and Malacic V.: Sediment transport and resuspension due to combined motion of wave and current in the northern Adriatic Sea during a Bora event in January 2001: a numerical modeling study, Cont. Shelf Res., 27, 613-633, 2007.

Zavatarelli, M. and Pinardi, N.: The Adriatic Sea modelling system: a nested approach, Ann. Geophys., 21, 345-364, doi:10.5194/angeo-21-345-2003, 2003. 